\title{
A LINGUAGEM DOS LIVROS DIDÁTICOS DE BIOLOGIA PARA A EDUCAÇÃO DE JOVENS E ADULTOS DO ESTADO DO RIO DE JANEIRO
}

\section{The language of the teaching books of biology for the education of youth and adults of the state of Rio de Janeiro}

\section{El lenguaje de los libros didácticos de biología para la educación de jóvenes y adultos del estado del Río de Janeiro}

\author{
Josete Rocha Do Santos ${ }^{\star}$ \\ Andréa Costa da Silva**
}

\begin{abstract}
Resumo
Ao longo da história das políticas educacionais no Brasil, a educação de jovens e adultos (EJA) foi influenciada pelas intencionalidades, interesses e conflitos entre as classes sociais por meio dos vários segmentos do estado ou da sociedade civil. As propostas recentes para o ensino de ciências - Diretrizes Curriculares Nacionais para o Ensino Médio (Resolução N2/2012) - preveem um ensino de biologia pautado no cotidiano do aluno jovem e adulto, por meio de uma linguagem que o possibilite a tomar decisões conscientes a partir do conhecimento científico. Com base neste aspecto, o objetivo deste artigo, uma parte da tese de doutorado, em andamento, é analisar a linguagem do livro didático de biologia, direcionado à EJA, a fim de compreendermos como o jovem é objetivado, neste material educativo, e como este livro, artefato cultural, instrumento de poder, onde há um conhecimento científico está materializado. Para tanto, adotamos a análise crítica do discurso (Chouliaraki \& Fairclough, 1999; Fairclough, 2003) por oferecer visibilidade crítica às relações que contemplem a problematização sobre questões de raça, gênero e diferenças de classes sociais, presentes neste suporte didático. As nossas análises textuais mostraram que o livro didático de biologia, direcionado para o jovem e adulto trabalhador, que frequenta a EJA, apresenta um paradoxo ontológico: um enunciador que tenta se aproximar do aluno por meio da linguagem, porém, ainda, desconsidera o conhecimento trazido por este aluno.
\end{abstract}

Palavras-chave: linguagem; livro didático de biologia; educação de jovens e adultos.

\footnotetext{
* NUTES/UFRJ. rochajosetefreitas@gmail.com

** NUTES/UFRJ. acostadasilva@gmail.com
} 


\section{Abstract}

Throughout the history of educational policies, in Brazil, Youth and Adult Education (EJA) was influenced by the intentionalities, interests and conflicts between social classes through the various segments of the State or Civil Society. Educational work, involving scientific language, was not a priority. However, the recent proposals for Science Teaching-National Curriculum Guidelines for Secondary Education (Resolution N2 / 2012)-provide for a Biology teaching based on the daily life of the young and adult student, through a language that enables him to take decisions based on scientific knowledge. Based on this aspect, the aim of this article, a part of the doctoral thesis, is to analyze the language of the didactic book of Biology, directed to the EJA, in order to understand what young is objectified in this didactic material and how this didactic book, cultural artifact, instrument of power, where there is a scientific knowledge, mediated by a teacher / author, who believes to stop the knowledge, is materialized. For this, we adopted the Critical Discourse Analysis (Chouliaraki and Fairclough (1999) and Fairclough (2003a) for focusing the oppressive relations of race, gender, and social class differences present and proposing changes to the socio-political landscape. textbooks have shown that the Biology textbook, directed to the young and adult worker, that attends the EJA, presents an ontological paradox: an enunciator that tries to approach the student through language, but also disregards the knowledge brought by this student.

Key words: language; biology textbook; youth and adult education.

\section{Resumen}

A lo largo de la historia de las políticas educativas en Brasil, la educación de jóvenes y adultos (EJA) ha sido influenciada por intenciones, intereses y conflictos entre las clases sociales a través de los diversos segmentos del estado o de la sociedad civil. Las recientes propuestas para la educación científica - Directrices curriculares para la educación secundaria (Resolución N2 / 2012) [MA1] - anticipan una enseñanza de la biología [MA2] basada en la vida cotidiana de los estudiantes jóvenes y adultos, a través de un lenguaje que permita tomar decisiones conscientes a partir del conocimiento científico. Con base en este aspecto, el objetivo de este artículo, parte de la tesis doctoral en curso, es analizar el lenguaje del libro de texto de biología, dirigido a EJA, para comprender cómo se objetiva al joven en este material educativo y cómo este libro, artefacto cultural, instrumento de poder, donde hay conocimiento científico se materializa. Para eso, adoptamos el análisis crítico del discurso (Chouliaraki \& Fairclough, 1999; Fairclough, 2003) [MA3] porque ofrece visibilidad crítica a las relaciones que contemplan la problematización sobre cuestiones de raza, género y diferencias de clase social, presentes en este apoyo didáctico. Nuestros análisis textuales mostraron que el libro de texto de biología, dirigido al trabajador joven y al adulto que asiste a EJA, presenta una paradoja ontológica: un enunciador que trata de acercarse al estudiante a través del lenguaje, pero que ignora el conocimiento traído por este estudiante.

Palabras clave: lenguaje; libro de texto de biología; educación de jóvenes y adultos. 


\section{Introdução}

Propostas curriculares recentes - Diretrizes Curriculares Nacionais para o Ensino Médio (Resolução N2/2012) apontam para a importância da educação em ciências para a formação de alunos aptos a compreenderem a cidadania como participação social e política. Estas propostas incentivam a elaboração de materiais educativos para a educação de jovens e adultos (EJA) que visem à formação de indivíduos críticos e inseridos numa sociedade na qual o conhecimento científico e tecnológico seja, cada vez mais, valorizado. Com base nisso, apresentamos uma análise de excertos de livros didáticos da Secretaria Estadual de Educação do Rio de Janeiro, Brasil (SEEDUC) direcionados à EJA.

Os textos podem ser definidos como a realização linguística na qual os discursos se manifestam e expressam outros discursos vinculados a práticas sociais que estão, na maioria das vezes, em competição (Fairclough, 2003). Em nossa pesquisa, procuramos aliar estes textos dos livros de biologia a fatores sociais, históricos, políticos, em torno da relação entre o ensino de ciências, a EJA e o currículo mínimo de ciências para a EJA. Essas três vertentes se unem pelo fato de o ensino de ciências, no século xxI, ter a proposta de proporcionar ao aluno um conhecimento prático, esclarecedor e aliado ao seu cotidiano. No caso, direcionamos este ensino para alunos da EJA, já prejudicados em seu percurso escolar, por não terem estudado na faixa etária própria (Carrano et al., 2015). Portanto, analisar a linguagem do livro didático de ciências, em especial, de biologia, se faz importante para compreendermos como este aluno está representado. 0 modo como a linguagem é veiculada no livro é fundamental para entendermos que ensino é dado ao público da EJA.

Neste estudo, por meio da análise crítica do discurso (Chouliaraki \& Fairclough, 1999; Fairclough, 2001, 2003), objetivamos analisar a linguagem do livro didático de biologia, direcionado à EJA, ensino médio, para compreender que jovem é representado neste material educativo, e como este livro, artefato cultural, perpassado pelo poder, está materializado. Estudamos as modalidades verbais deôntica, epistêmica e categórica, que evidenciam a forma como o autor do texto se posiciona diante dos enunciados, e como estes enunciados se organizam, por vezes de forma normativa e autoritária, não favorecendo a construção de posturas críticas emancipatórias, ou de forma a ampliar a visão de mundo do aluno e fazê-lo optar conscientemente. Essa concepção de mundo do enunciador, expressa no livro didático pelos verbos modais dever e poder, principais verbos que caracterizam a modalidade analisada, podem apontar para preconceitos acerca de supostas deficiências culturais, por parte dos alunos, no âmbito do letramento científico emancipatório (Soares, 2006; Martins, 2008).

A seguir, apresentamos um breve panorama sobre o livro didático como mediador de saberes, em uma revisão da literatura sobre o assunto já estudado em nosso país.

Em seguida, dissertamos acerca de um panorama histórico da EJA no Brasil, algumas considerações sobre o ensino de ciências, dentro do qual se insere o livro didático de biologia e, adiante, explicamos o arcabouço teórico-metodológico no qual se baseia a análise crítica do discurso. Após isso, apresentamos os resultados e as discussões inerentes.

Nossas análises buscam estabelecer relações entre elementos da conjuntura social, histórica, política, e as formulações presentes, no livro didático de biologia, que interagem dentro deste gênero textual específico e nos ajudam a perceber como o aluno jovem e adulto é objetivado em contextos ligados à saúde e ao meio ambiente.

\section{Algumas considerações sobre o livro didático no Brasil}

Vários autores se detêm em estudar a história do livro didático no Brasil. Bittencourt (2004) evidencia a questão da autoria neste suporte de leitura e faz referência a Chartier (1997) como um dos estudiosos que recuperam a contribuição de Foucault no ensaio "O que é ser um autor". Nessa obra, segundo Chartier (1997), Foucault destaca a função do autor que, ao publicar uma obra, torna-se responsável pela sua autoria e se compromete socialmente com isso. Bittencourt (2004, p. 478) concorda com Chartier e argumenta que, no tensionamento com o mercado editorial, o livro escolar é considerado, por vezes, como uma obra "menor", um trabalho secundário no âmbito acadêmico. Inicialmente produzido para professores, o livro didático passou a ser, também, do aluno e, nesse processo, em virtude do público escolar e de haver necessidade de referências pedagógicas, o cuidado com a linguagem passou a ser essencial. Há, assim, a necessidade de existir a inclusão, no livro didático de fontes documentais e científicas para relativizar o lado pessoal do autore enfocar o aspecto científico dos conteúdos apresentados. Sob tal perspectiva, as informações mais pessoais, que ultrapassam aspecto didático, poderiam constar somente nos prefácios, prólogos e nas introduções. 
Ainda sob o enfoque historiográfico, temos o estudo de Munakata (2012) acerca de várias pesquisas em torno do livro didático. $O$ autor afirma que, entre os anos de $2001 \mathrm{e}$ 2011, houve cerca de 800 trabalhos sobre o livro didático e o estudo de Bittencourt (1993) foi o impulso inicial para a vasta produção de pesquisas nas décadas seguintes.

Na visão de Munakata (2012), o livro didático, como produto específico destinado à escola, adequa-se a este espaço e não há como controlar a sua influência em termos de ideias vinculadas ao seu uso em sala de aula. 0 autor, ao analisar a produção de uma editora de livros para a EJA, constata que estes livros não passam de versões reduzidas de seus similares para o ensino regular. Desta forma, examina os aspectos editorias, tais como diagramação, tamanho dos textos e a utilização das ilustrações para a falta de zelo com que os livros da EJA são produzidos, um sinal também da precariedade como é vista essa modalidade de ensino (Munakata, 2012). Chopin (2004) é outro autor que se preocupa em debater sobre as principais dificuldades identificadas pela pesquisa histórica nos livros e nas edições didáticas com destaque. Para as tendências atuais, destaca como o setor escolar tem assumido, na economia editorial, um peso considerável nestes dois últimos séculos. Para o autor, em um país como o Brasil, os livros didáticos correspondiam, no início do século xx, a dois terços dos livros e representavam, ainda, em 1996, aproximadamente $61 \%$ da produção nacional. Nos últimos tempos, este percentual não tem aumentado devido às incertezas quanto ao futuro do livro impresso e, particularmente, em relação ao papel que os livros didáticos vão desempenhar diante das novas tecnologias educativas (Chopin, 2004).

É interessante destacar, neste trabalho, as quatro funções dos livros escolares propostas pelo autor, assumidas conjuntamente ou não e que variam segundo o ambiente sociocultural, a época, as disciplinas, os níveis de ensino, os métodos e as formas de utilização. Segundo Chopin (2004), os livros didáticos possuem as funções referencial, instrumental, ideológica e cultural e documental. O livro didático tem função referencial por conter os conteúdos educativos que um grupo social acredita ser importante transmitir às futuras gerações. Tem função instrumental porque o livro didático propõe exercícios ou atividades para facilitar a aquisição dos conhecimentos e favorecer a ampliação de competências disciplinares ou de conteúdos transversais. Possuem função ideológica ou cultural, a mais antiga, por se constituir o livro sempre, ao longo dos tempos, como um instrumento de construção de identidades já que há nele questões da língua, da cultura e dos valores das classes dominantes. Essa função tende a influenciar as gerações mais jovens de forma explícita ou implícita. Finalmente, o livro tem uma função documen- tal por ser possível formar um conjunto de documentos, textuais ou imagéticos, que incentivem a observação ou o debate podendo vir a desenvolver o espírito crítico do aluno e ampliar a sua autonomia.

Sob outra perspectiva, Hoffman e Scheid (2007) também veem o livro didático como uma ferramenta importante, para o processo de ensino-aprendizagem, mas argumentam que deve haver a preocupação dialógica, por parte do autor, em trabalhar metáforas e analogias para estimular o raciocínio dos alunos, estabelecendo interlocuções com o conteúdo apresentado e traçando relações com o seu cotidiano. As autoras partem do seguinte pressuposto: "o recurso ao raciocínio analógico auxilia na compreensão do conhecimento científico se o objetivo for estruturar, esclarecer e avaliar o novo conteúdo a partir do conhecimento já adquirido antes" (Hoffman \& Scheid, 2007, p. 23). Assim, as autoras investigam os livros didáticos usados em cinco escolas públicas de um município, localizado no noroeste do estado do Rio Grande do Sul, Brasil, e constatam pautando-se no estudo das nove categorias de analogias, propostas por Ferraz e Terrazzan (2001), que as analogias são ferramentas didáticas essenciais para ajudarem a construir o conhecimento científico dos alunos na área biológica. Muitas vezes, essas analogias e metáforas aparecem, de forma diferenciada, para aproximar o aluno-leitor do conhecimento científico, com o uso de fatores comuns ao seu cotidiano, e se tornam, assim, elementos que facilitam a aprendizagem. Por outro lado, se não são adequadamente explicitadas, "tornam-se fatores complicadores no processo de aprendizagem dos conceitos científicos e podem levar, inclusive, o aluno a produzir/reforçar erros conceituais" (Hoffman \& Scheid, 2007, p. 35).

Para Selles et al. (2013), os livros didáticos são produções escolares que expressam os sentidos das práticas curriculares, bem como produzem significados sobre as definições do que é ensinado, da forma como é ensinado e de como a formação docente deve ser desenvolvida. Na visão das autoras, o livro didático resulta de uma complexa estrutura de produção e de significação que abrange variadas instâncias dos sistemas educacionais. Concordamos com as autoras ao dizerem que há várias instâncias ou vozes (Bakhtin, 2000), representadas nos livros didáticos tais como o governo, os órgãos oficiais, as instituições de ensino superior, os autores dos livros, as editoras, os professores, que os adotam em suas aulas, e os alunos que os usam e os ressignificam em suas atividades na escola.

Com base em tais perspectivas, pensamos o livro didático, em sua materialidade e no circuito cultural e educacional no qual está inscrito: destinado à EJA, modalidade educacional repleta de características e peculiaridades, e cujo histórico sintetizamos a seguir. 


\section{Um breve panorama histórico da educação de jovens e adultos (EJA)}

Pensar sobre a origem da EJA, associada à criação do nosso sistema público de ensino brasileiro, é essencial para entendermos o percurso histórico de construção desta especificidade de ensino e como isso repercute, atualmente, nos materiais educativos para a EJA, em especial o livro didático de Biologia.

Ao longo da história, as ações de educação de jovens e adultos sempre estiveram presentes no contexto brasileiro. No Brasil-Colônia, pode-se encontrar as primeiras formas de educação junto ao público adulto, principalmente, indígenas e negros, realizadas pelos jesuítas por meio da catequese. Amaral $(2000$, p. 8$)$ ressalta a intencionalidade da difusão do catolicismo, como forma de abrandamento das resistências aborígines e do combate aos cultos africanos, para convertê-los em cristãos submissos e acomodados. Já tínhamos, assim, o início da educação de jovens e adultos no Brasil. Assim, Amaral (2000, p. 8) explica que:

\footnotetext{
Com a Reforma Pombalina - junho de 1759 -, após a expulsão dos jesuítas da Colônia e a vinda da família real para o Brasil, encontramos, em 1876, registros da difusão do ensino noturno para adultos no país, denominado, então, como educação popular. Esta não terá significativo investimento até os primeiros 25 anos do regime republicano, considerando que a população do campo (maior parte da população brasileira no período), submetida aos laços paternalistas e de dominação política pelos donos da terra (elites oligárquicas), não sentia a instrução como uma necessidade imediata. A escolarização passa a se tornar critério de ascensão social, com a Lei Saraiva de 1882, incorporada à Constituição Federal de 1891, em que o voto será vetado ao analfabeto e facultado, apenas, aos candidatos e aos eleitores que "dominassem" as técnicas de leitura e escrita e não somente pelo critério de renda como ocorria anteriormente.
}

No início do século xIX, a evidenciação dos altos índices de analfabetismo refletia uma realidade vergonhosa para a intelectualidade brasileira. Entendia-se a necessidade de se colocar o Brasil entre os "países cultos". Comparando-se à situação educacional de países como os Estados Unidos, e na América Latina, Argentina e Uruguai, o Brasil estava em desvantagem (Alvarenga, 2010).
Na década de 1920, prenuncia-se a mobilização em torno do analfabetismo como um problema educacional, no

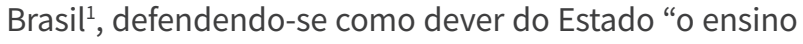
das classes laboriosas", preocupando a muitos com "a difusão do ensino como instrumento da estrutura de poder a fim de evitar os problemas de convulsão social e de dar solução aos grandes problemas agitados, desordenadamente, pelos socialistas" (Paiva, 1983, p.45).

Somente a partir de Paulo Freire, com o seu trabalho inovador a partir de 1963, a educação de adultos passa a ser mais do que uma alfabetização com um fim único. Esse educador propunha um ensino coerente entre os conteúdos e a vida dos alunos para possibilitar uma consciência crítica sobre os fatos do mundo.

Por apresentar uma proposta pedagógica libertadora do indivíduo, que não interessava à elite, muito menos ao regime militar, Paulo Freire foi preso e exilado e, em 1967, foi instituído o Movimento Brasileiro de Alfabetização (MOBRAL), que, bastante diferente da proposta freiriana, condicionava o indivíduo ao seu status quo (Amaral, 2000).

Em 2000, as Diretrizes Curriculares Nacionais (Parecer CEB 11/2000) estabeleceram que a EJA deve ter as funções: reparadora, equalizadora e qualificadora. Mas como reparar, equalizar e qualificar um público já tão extirpado ao longo da história? Como estes indivíduos podem ter a mesma ascensão se não estudaram no mesmo período que os outros estudantes que tiveram acesso na idade regular? Estes questionamentos, que se contrapõem às Diretrizes Curriculares, nos advém a partir do proposto por Carrano et al. (2015). Para este autor, os alunos da EJA são indivíduos com as "trajetórias truncadas".

Boa parte dos jovens viveu experiências de abandono da escolarização, em algum ponto de sua trajetória escolar, sendo este um dos principais fatores da distorção idade-série. É interessante analisar, neste momento, o que esses sucessivos abandonos e reingressos revelam a respeito das expectativas desses jovens diante do futuro. (Carrano et al, 2015, p. 1449)

$\mathrm{Na}$ fase em que deveriam estar frequentando a escola, foram trabalhar, por questões econômicas e sociais e, somente após muito esforço, voltam à escola. Estes jovens, em sua maioria, negros e morando em comunidades, na periferia dos grandes centros, acordam cedo para o trabalho, estudam à noite, já cansados do dia, e

1 Paiva (1983) argumenta que a obra de José Verísssimo, denominada "A educação nacional" (1980), e o primeiro trabalho de Carneiro Leão, denominado "A educação" (1909), foram marcantes para o debate em torno do analfabetismo no Brasil. 
sonham em terminar o ensino médio para ingressarem em uma universidade. No entanto, o cansaço, em virtude da labuta diária, e os compromissos familiares causam as sucessivas evasões escolares (Carrano t al-, 2015).

Catelli (2016) nos alerta para o fato de a tentativa de equalizar, socialmente, estes jovens e adultos da EJA, mencionados por Carrano (2015), ao ensino regular, proposto pelas Diretrizes Curriculares Nacionais, não ser prioridade na Base Nacional Curricular Comum (BNCC) de 2015, onde não há nenhuma referência à EJA. Porém, na versão da BNCC, de abril de 2016, houve um esforço para mencioná-la, mas isso foi feito de forma muito superficial (Catelli, 2016). Nesse documento, o currículo foi tratado de forma homogênea sem considerar a especificidade deste público, já vivendo diversas situações de exclusão relacionadas a aspectos raciais, de gênero, de faltas de condições mínimas para permanecer na escola. Além do mais, segundo o autor, há poucos recursos direcionados a esta modalidade de ensino em virtude do desinteresse das várias gestões públicas em dar atenção a um currículo nacional adequado aos sujeitos da EJA. Talvez, esta falta de um olhar mais atento seja mais um motivo para aumentar, consideravelmente, a evasão nas salas de aula da EJA (Catelli, 2016).

Diante do exposto, pensar em um ensino de ciências que contribua, efetivamente, no sentido de associar a experiência de vida e de trabalho, deste público, ao saber científico, pode ser o ponto de partida para a mudança.

\section{Um ensino de ciências voltado para formar seres atuantes}

Ao abordarmos a trajetória do ensino de ciências, no Brasil, mostramos a necessidade de se cumprir um currículo mínimo para a EJA conforme está descrito na página da SEEDUC ${ }^{2}$.

No início do século xx, o ensino de ciências era orientado, principalmente, por motivações de caráter humanista (Cachapuz, 1999). Krasilchik (2000) nos diz que o ensino de ciências, seguindo uma linha positivista, pautava-se em normatizações e visava a permitir que os sujeitos se ajustassem à sociedade e contribuíssem, alienadamente, para a manutenção das relações sociais já estabelecidas. Em meados do século xx, em virtude da influência dos projetos de ensino, nacionais e internacionais, que valorizavam o papel do método e da construção de práticas e do raciocínio científico, houve a necessidade de se estabelecer as etapas do método científico: identificação de problemas,

2 Currículo Mínimo para a Educação de Jovens e Adultos www.rj.gov.br/web/seeduc/exibeconteudo elaboração das hipóteses em relação a este problema, a verificação experimental dessas hipóteses, elaboração de uma conclusão para se passar ao levantamento de novas questões e, assim, a ciência avançar sempre (Krasilchik, 2000). Entretanto, após 1964, durante a ditadura militar, o ensino passou a ter um caráter profissionalizante e as disciplinas científicas tiveram sua importância diminuída e descaracterizada nos currículos. Este quadro é, parcialmente, revertido, a partir da década de 1980 , por meio do crescimento do construtivismo, da preocupação de que o ensino de ciências pudesse promover a democratização do conhecimento científico, do reconhecimento da relação intrínseca entre ciência e sociedade e da preocupação com a qualidade da "escola para todos" (Krasilchick, 2000, p. 89). Para a autora, é nesta época que as ideias prévias dos alunos passam a ter centralidade nas discussões sobre a aprendizagem de ciências.

Cachapuz (1999) evidencia que a, partir dos anos 1990, tanto no Brasil, quanto no exterior, houve a ampliação do leque de perspectivas teóricas que passam a influenciar o ensino de ciências. Esta fase, denominada por Cachapuz (1999) de "pós-mudança conceitual", é composta por trabalhos onde o ensino de ciências foi recontextualizado baseado na revisão epistemológica da "nova sociologia da ciência". Com essa nova visão, passou-se a propor um ensino pautado no trinômio Ciência, Tecnologia e Sociedade (CTS). Nesta abordagem, não somente a escola é considerada um espaço formativo, mas também os museus, os teatros, os centros culturais e outros lugares. $O$ aspecto da democratização do acesso ao conhecimento e da justiça social amplia-se, desde o referido período, e, no contexto da globalização, apresenta-se como enfoque central da agenda para o século xxI.

Segundo Krasilchick (2000, p. 86), cada uma destas tendências, e consequentes objetivos, para o ensino de ciências acarretaram mudanças no perfil do indivíduo a ser formado: do cidadão pertencente a uma elite, passamos a ter o cidadão trabalhador até chegarmos a ter o cidadão-trabalhador-estudante.

Então, dentro deste viés, retomar a Resolução CNE/CEB $11 / 2000$ e o Parecer CNE/CEB 11/2000, é importante para analisarmos o Currículo Mínimo para Ciências, direcionado à EJA, que consta na página da SEEDUC:

Pauta-se nos princípios da equidade, da diferença e da proporcionalidade para tornar o aluno um ator social com o compromisso de ajudar na construção de uma sociedade mais justa e solidária, respeitando as diversidades de gênero, raça, etnia, religiosidade e sexualidade para identificar-se como sujeito de seu próprio viver. 
O Currículo Mínimo de Ciências Naturais para a Educação de Jovens e Adultos, Ensino Médio, do Estado do Rio de Janeiro, para a disciplina de Biologia, propõe conteúdos que procuram considerar as particularidades desta modalidade de ensino. Propostos por um grupo de profissionais, conforme explicado na página da SEEDUC, há uma associação entre os conteúdos e as habilidades essenciais ao estudo de Biologia a serem apreendidas pelo aluno. Esta proposta atual se baseia nas Diretrizes Nacionais para a EJA e nos Parâmetros Curriculares Nacionais. Procura, no entanto, representar um agrupamento sequencial dos conteúdos de modo a destacar os aspectos essenciais da vida na Terra, articulando habilidades à realidade, ao mundo trabalhista e às novas tecnologias. Considera-se que o Currículo Mínimo não impede a liberdade dos professores para se constituírem colaboradores de fato, em sala de aula, tornando, assim, a aula de Biologia muito mais interessante.

\section{Metodologia}

\section{O arcabouço teórico-metodológico da análise crítica do discurso}

Para analisarmos a linguagem dos excertos do livro de Biologia, baseado no Currículo Mínimo, comentado acima, adotamos o arcabouço teórico-metodológico da análise crítica do discurso (ACD), propostos por Chouliaraki e Fairclough (1999). Esta abordagem considera a conceituação da vida social como um sistema aberto e a noção de mundo social constituída de práticas articuladas, denominadas "práticas discursivas". Essas estão pautadas na vida social, nos domínios da economia, da política, da cultura, incluindo a vida cotidiana. As práticas discursivas fazem parte das práticas sociais, caracterizadas pela articulação de quatro elementos: discurso, relações sociais, fenômeno mental - crenças, valores, desejos, ideologias $-\mathrm{e}$ atividade material.

Para Fairclough (2003), a ACD baseia-se em um aspecto ontológico social realista: os eventos concretos e as estruturas sociais são vistas como parte da realidade social. Ou seja, não há eventos, estruturas sociais e nem práticas discursivas desarticuladas entre si.

Na condição de ciência social crítica, a ACD tem objetivos emancipatórios e busca enfocar os chamados "excluídos" dentro de certas formas da vida social - os pobres, os sujeitados a relações opressivas de raça, gênero e outros. Daí, o nosso interesse em mobilizá-la na análise de materiais didáticos, direcionados a alunos da EJA, normalmente trabalhadores impossibilitados de estudarem na faixa etária regular.
Enfim, a análise crítica do discurso, perspectiva teórico-metodológica desta pesquisa, se caracteriza como inserida na teoria crítica $^{3}$, perspectiva epistemológica que sempre aponta para uma necessidade de mudança em um panorama sócio-político, e tem os seguintes aspectos como premissas:

Todo conhecimento está influenciado por relações de poder que são de natureza social e estão constituídas historicam ente. Assim, os fatos históricos nunca podem ser descontextualizados do campo dos valores e da ideologia.

A relação entre conceito e objeto e entre significante e significado não é estável e, frequentemente, se encontra influenciada pelas relações sociais da produção capitalista e do consumo.

A linguagem é fundamental na formação da subjetividade, tanto do conhecimento consciente quanto inconsciente. (Esteban, 2010, p. 69)

Pela explicação, é coerente que toda análise realizada parta da percepção de um problema que, em geral, baseia-se em relações de poder, na distribuição assimétrica de recursos materiais e simbólicos, em práticas sociais, na naturalização de discursos particulares, conforme dito antes, considerados universais (Fairclough, 2003).

A pesquisa em ACD apresenta três etapas. A primeira etapa é a da análise textual: estudo do vocabulário, da gramática, dos elementos de coesão das orações e da estrutura do texto. A segunda etapa consiste em explicar a prática discursiva concernente, em nosso caso, à produção, distribuição, e consumo do livro didático, etapa melhor aprofundada em nossa tese de doutorado e que, neste trabalho, abordamos inicialmente. A terceira etapa do modelo tridimensional, proposto por Fairclough (2001), consiste em descortinar a ideologia e a hegemonia vigente que está subjacente aos textos. A análise textual é a etapa que dá suporte para descortinar a ideologia e a hegemonia subjacentes, pois todo texto tem um caráter ideológico (Bakhtin, 1992). Deve-se mostrar possibilidades de mudança e superação dos problemas identificados, por meio das contradições das conjunturas. Para terminar, toda pesquisa, em ACD, deve conter uma reflexão sobre a análise, isto é, toda pesquisa crítica deve ser reflexiva.

3 Um dos objetivos fundamentais da Escola de Frankfurt era emancipar, intelectualmente, o indivíduo das amarras de um pensamento racional que instrumentaliza o sujeito, impulso que se estruturou na denominada Teoria Crítica (Esteban, 2010, p. 68). 
Deste modo, quando observamos como os jovens são objetivados nos livros didáticos da EJA, buscamos evidenciar através da análise textual, por meio dos verbos modais " "poder" e "dever", os principais verbos para expressar modalidade epistêmica ou deôntica, respectivamente, e verbos no presente, que caracterizam modalidade categórica (Fairclough, 2001). Para descortinarmos como os livros didáticos de biologia, ensino médio, estão elaborados pela Secretaria Estadual de Educação, para o Ensino de Jovens e Adultos no Estado do Rio de Janeiro. E nos questionamos: tais livros produzem um saber científico crítico ou os conteúdos de ciências reforçam preconceitos, sobre supostas deficiências, em relação ao aluno da EJA? Os conteúdos científicos levam a contextos de participação social, incentivando o aluno a se apropriar de um pensamento crítico-emancipatório para se tornar um agente transformador, um cidadão, no sentido político da palavra, na sociedade em que vive? Ou seja, estudamos o texto para entendermos a prática social na qual há a inserção do livro didático de biologia, um artefato cultural, que contém conhecimento e é perpassado por relações de poder.

\section{Modalidade: possibilidades e obrigatoriedades}

Fairclough (2003) parafraseia Bakhtin ao dizer que "a linguagem é investida de ideologia". Sendo assim, ao analisarmos o texto, é preciso termos em mente os efeitos sociais mediados pela construção de significados. A ênfase das nossas análises está no significado identificacional - subdividido nas categorias modalidade e avaliação - proposto por Fairclough (2003). Desta forma, analisamos formulações marcadas pelas modalidades verbais deôntica, epistêmica e categórica, e como se organizam, discursivamente, para indicar como o discurso científico-escolar é representado: de forma normativa e autoritária (modalidade deôntica e modalidade categórica) ou de forma aberta e suscetível a ampliar o conhecimento (modalidade epistêmica), nos textos mobilizados como elemento relevante para a tomada de decisão.

A análise atentou para o emprego do verbo modal "dever", que caracteriza modalidade deôntica, expressam obrigação ou necessidade, e do verbo "poder", que caracteriza modalidade epistêmica, que expressa possibilidade, bem como para o emprego de verbos, em geral, no presente do indicativo, sinalizando modalidade categórica, expressando certeza.

4 Verbos modais são verbos especiais, ligados à modalidade, e estão associados à opinião ou julgamento de quem escreve ou fala sobre alguma coisa (Palmer, 1986, p. 33).
Fairclough (2003) define a modalidade epistêmica como o comprometimento com o conhecimento já comprovado. Ao se referir ao comprometimento, expressando ideia de obrigatoriedade/necessidade, denomina a modalidade como deôntica.

Fairclough acrescenta a modalidade categórica como aquela que apresenta grau de assertividade e certeza, evidenciando alto grau de comprometimento do enunciador com as suas afirmações.

No tópico a seguir, apresentamos os resultados e discussões em torno da modalidade quanto ao uso dos verbos modais "dever" e "poder" no livro didático de biologia do ensino médio. Este aspecto da linguagem vai nos ajudar a perceber como o aluno é representado no livro, material discursivo e produtor de discursos e que pode apresentar divergência entre o aluno imaginário, a quem editores $\mathrm{e}$ autores se referem, e o jovem que está na escola, a quem não têm acesso.

\section{Resultados e discussões}

\section{O material empírico}

O nosso estudo tem enfoque no módulo de Ciências da Natureza, dividido em biologia, química e física, ensino médio para a EJA do Estado do Rio de Janeiro, Brasil. Focamos a nossa análise no livro de biologia por haver uma maior materialidade discursiva.

O contexto em que foi criado é resultante de uma proposta de elaboração de materiais didáticos, em 2013, para a EJA, implantada pelo Governo do Estado do Rio de Janeiros. Esta proposta previa a elaboração de materiais didáticos, livros e recursos multimídia, pela Secretaria Estadual de Educação em parceria com a Fundação Centro de Ciências e Educação Superior (Cecierj). A finalidade deste material era atender à demanda específica da EJA: apresentar conteúdos didáticos a esta parcela da população, estudantes a partir dos 18 anos, conforme a LDB, que não puderam ter acesso ao ensino regular, conforme discussão anterior, ou por terem que se inserir no mercado de trabalho, antes do tempo, ou por outra razão.

O módulo de Ciências da Natureza foi organizado em dois volumes. 0 volume 1 está composto por 5 unidades e contém 148 páginas envolvendo conteúdos e exercícios. Listamos as unidades dos volumes 1 referentes aos conteúdos de Biologia:

\footnotetext{
5 Fonte www.rj.gov.br/web/seeduc
} 


\author{
Sumário ${ }^{6}$ \\ Biologia \\ Unidade 1 - O corpo, a pele, os músculos e o esqueleto \\ Unidade 2 - Sistemas respiratório e circulatório \\ Unidade 3 - Sistemas nervoso e imunológico \\ Unidade 4 - Sistema urogenital \\ Unidade 5 - Sistema digestório
}

O volume 2 possui 5 unidades e contém 126 páginas envolvendo conteúdos e exercícios. Listamos as unidades do volume 2 referentes aos conteúdos de Biologia:

\section{Biologia}

Unidade 1 - A energia do dia a dia

Unidade 2 - Interações ecológicas - a teia da vida

Unidade 3 - País tropical e bonito por natureza: os diferentes biomas

Unidade 4 - A árvore e os arbustos da vida

Unidade 5 - Cerveja, pão, Zé Gotinha, soja e uma certa ovelha chamada Dolly: a biotecnologia

Como critério para estabelecer um recorte temático, para as nossas análises, promovemos uma articulação entre as questões relacionadas à saúde e ambiente que pudessem levar o aluno a refletir sobre atitudes do cotidiano envolvendo tomadas de decisão. Verificamos os excertos, ligados à saúde e ao ambiente, nos quais os verbos "poder" e "dever" estivessem presentes.

Baseamos o recorte no seguinte procedimento metodológico: leitura exaustiva de todos os textos a fim de identificarmos os contextos nos quais o texto privilegiava i) temas relacionados à saúde e ao ambiente, ii) contextos que poderiam envolver a tomada de decisões, e iii) associações entre estes dois aspectos.

Recortamos parágrafos nos quais havia estas referências para registrar aspectos do contexto temático imediatamente anterior e posterior ao trecho específico no qual tal associação foi notada. Decidimos por não analisar elementos imagéticos uma vez que isto demandaria a mobilização de outros referenciais teórico-metodológicos.

6 O sumário dos dois volumes do Módulo 4 Ciências da Natureza está dividido em unidades, que listamos acima. As seções, que fazem parte de cada unidade, não são citadas no sumário.

\section{Categorias e procedimentos de análise}

- Seleção das categorias relevantes para a análise textual: escolhas léxicas voltadas para a modalidade verbal - verbos "poder" e "dever" - principais para expressar modalidade.

Selecionamos, de acordo com Fairclough (2003), a categoria de análise modalidade, por ela estar ligada à forma como os locutores se comprometem com seus enunciados, sendo, por isso, um elemento importante para revelar relações entre interlocutores em situações de troca de conhecimento. Em outras palavras, a forma como representamos o mundo expressa o grau de comprometimento com a verdade. É parte de como nos identificamos - significado identificacional (Fairclough, 2003) - necessariamente, na relação com os outros com quem interagimos.

Assim, o estudo da modalidade, por meio do uso dos verbos "poder" e "dever", se torna importante para distinguirmos os diferentes níveis e graus de comprometimento, atribuídos aos enunciados de Biologia, bem como a forma pela qual o enunciador, que representa a voz do conhecimento científico-escolar, se autoidentifica e vê o outro com quem dialoga, no caso, o aluno da EJA.

\section{Como o conhecimento científico é representado no livro de biologia da EJA?}

Mostramos como os conteúdos científicos estão relacionados aos aspectos de conhecimento e certeza (modalidade epistêmica), conhecimento e assertividade (modalidade categórica) e conhecimento e necessidade (modalidade deôntica) em contextos associados à tomada de decisão, nos livros de biologia da EJA, e como esses detalhes da linguagem encaminham o raciocínio do aluno para uma forma aberta e suscetível ao conhecimento ou para uma forma normativa e autoritária.

Nos excertos, destacamos as escolhas lexicais por meio dos verbos que expressam modalidade.

\section{Conhecimento e certeza que levam à tomada de decisão quanto à saúde}

O Plasmodium vive parte do seu ciclo de vida nas células das glândulas salivares do mosquito, as quais produzem saliva. Quando o Anopheles pica um ser humano, a sua saliva, repleta de parasitas, entra em contato com a corrente sanguínea humana. É dessa 
maneira que somos infectados pelo protozoário da malária.

O Plasmodium infecta, principalmente, nossas hemácias onde se reproduz e, de ciclos em ciclos, rompe essas células e fica livre na corrente sanguínea para infectar outras hemácias. Pode haver outras formas da doença, uma delas com comprometimento, inclusive, do sistema nervoso central.

Como os parasitos estão presentes, na circulação sanguínea, durante a infecção, a transmissão da malária também pode ocorrer a partir de transfusões de sangue, de transplantes de órgãos, da utilização compartilhada de seringas por usuários de drogas endovenosas ou da gestante para o filho (malária congênita) antes ou durante o parto.

Os sintomas mais comuns são: febre alta, calafrios intensos que se alternam com ondas de calor, muito suor, dor de cabeça e no corpo, falta de apettite, pele amarelada e cansaço. A prevenção da doença se dá, também, por meio da erradicação do mosquito vetor.

Fonte: Biologia da Nova EJA - Seção "Parasitas no sangue" - p. 53 Unidade Sistema Respiratório e Circulatório - Volume 1.

É evidente a preocupação do enunciador em usar um vocabulário da biologia: Plasmodium e Anopheles, evidenciando o nome científico do protozoário e do mosquito, o uso destes termos, que têm relação com a temática saúde e ambiente, expressa o compromisso didático de ampliar o conhecimento científico do estudante. Entretanto, seu emprego parece demandar uma habilidade do aluno fazer uma relação e compreender que o Anopheles é um mosquito. $O$ uso do presente do indicativo em "vive", "pica", "rompe" caracteriza o caráter regular e inequívoco do comportamento do mosquito, caracterizando uma modalidade categórica, e sugerindo esta característica como típica da descrição do comportamento de tais animais.

O uso do verbo modal "poder", caracterizando a modalidade epistêmica, expressa a noção de possibilidade na oferta de informação. A expressão "pode haver outras formas da doença" aponta para a "potencialidade, possibilidade, eventualidade". O mesmo ocorre ao dizer que "a transmissão da malária também pode ocorrer a partir da transfusão de sangue, de transplante de órgãos, da utilização compartilhada de seringas por usuários de drogas endovenosas". Assim, estes contextos se remetem a situações nas quais há, implicitamente, menção a situações que fogem ao controle do indivíduo, como no caso de receber uma transfusão de sangue infectado, e outras que podem envolver uma mulher ficar grávida sendo portadora de malária ou usuária de drogas injetáveis.

Ao selecionar este conteúdo, o enunciador pode estar evidenciando uma visão preconcebida de que o aluno leitor deste livro didático da EJA, provavelmente, vive em lugares sem saneamento básico e sem coleta de lixo. Em síntese, o uso do verbo modal "poder", associado à modalidade epistêmica, foi apresentado como forma de o enunciador mostrar o conhecimento científico ao aluno e apresentar algumas possibilidades de não contaminação. $\mathrm{O}$ uso de verbos no presente do indicativo, expressando modalidade categórica, também, foi um recurso muito usado, pelo autor, para imprimir o grau de certeza ao texto quanto aos conteúdos mencionados. Desta forma, o conteúdo de educação em ciências foi trabalhado numa linguagem para facilitar a compreensão e ampliar a visão do leitor sobre relações com os meios físico, econômico e sociocultural, a fim de o aluno ser capaz de identificar e se afastar dos fatores de risco à saúde pessoal e coletiva conforme vemos no trecho analisado. Percebemos que não há elaborações, entretanto para situar a discussão do controle e erradicação do vetor num contexto de ação ou tomada de decisão coletiva. A discussão se circunscreve somente ao âmbito individual. Também não houve uma discussão sobre o cuidado que as mulheres devem ter para não engravidarem em situações de risco, ao não uso de entorpecentes, em geral, e a não reutilização de seringas para evitar doenças e, no caso, a malária.

\section{Conhecimento e assertividade que levam à tomada de decisão quanto ao meio ambiente}

Ornitólogos (estudiosos do grupo das aves) já registram 510 espécies de aves na Caatinga, como o Acauã (Herpetotheres cachinnans), um gavião predador de serpentes, a Ararinha-azul (Cyanopsitta spixii), extinta na natureza pelo tráfico de animais silvestres, e o Galo-da-campina (Paroaria dominicana), um dos mais bonitos pássaros brasileiros.

Apesar da escassez de água e das muitas ameaças que os corpos hídricos da Caatinga sofrem (desmatamento das matas ciliares e contaminação por esgotos, agrotóxicos e efluentes indusitriais), foram registradas 240 espécies de peixes ( $57 \%$ endêmcias). Algumas delas têm uma incrível adaptação para viver em rios e lagos temporários: os ovos resistem à seca, durante os meses de estiagem, e eclodem no períodos mais úmidos. Por isso, esses peixes são conhecidos, popularmente, como peixes das nuvens ou peixe da chuva. 
Apesar disso, a fauna mais característica da Caatinga são os répteis e anfíbios (154 espécies no total). Há, também, 144 espécies de mamíferos na região (64 são espécies de morcegos e 34 de roedores). De acordo com a lista de animais ameaçados de extinção, 28 vivem na Caatinga. Ainda assim, este é o bioma menos estudado do país.

Entre as áreas de maior importância para a conservação estão a Bacia Hidrográfica do Rio São Francisco, o Raso da Catarina (BA), a Chapada do Araripe (CE, PE e PI), o Parque Nacional da Serra das Confusões (PI) e o Parque Nacional da Serra da Capivara (PI). Neste último, foi descoberto um sítio arqueológico com os mais antigos vestígios conhecidos da presença humana nas Américas (fogueiras, artefatos de pera e pinturas rupestres).

Aliás, o passado geológico da região é fascinante! O Rio São Francisco já formou uma imensa lagoa no interior do Brasil. A dinâmica da variação do seu curso, devido a alterações climáticas, nos últimos 2 milhões de anos, criou barreiras geográficas que isolaram populações, estimulando a formação de novas espécies (como você estudou na Unidade 5 do Módulo 1).

A Caatinga também é uma região de profundas desigualdades sociais, com os mais baixos índices de Desenvolvimento Humano (IDH). Eles são decorrentes de um processo de ocupação que explorou a Natureza de forma predatória, concentrando terra e poder no domínio de poucos. Uma região onde o acesso à água ainda não se consolidou como direito básico. Uma região com energia solar abundante e que abriga um complexo hidrelétrico que fornece energia para as grandes metrópoles nordestinas e para seu parque industrial. Mas onde $30 \%$ da energia consumida em residências, olarias e siderúrgicas são gerados por lenha, retirada da natureza de forma predatória.

Além do desmatamento, para o consumo de lenha, a Caatinga sofre, ainda, degradação ambiental pela pressão da pecuária extensiva, a agricultura de irrigação e pela exploração de minérios (como o polo gesseiro da Chapada do Araripe - CE).

Entre as ações prioritárias, para a conservação deste bioma, estão a recuperação das matas ciliares (especialmente as do Velho Chico), a ampliação das áreas de manejo sustentável e a criação de três corredores ecológicos, nas regiões de Peruaçu a Jaiba (MG), no sertão de Alagoas e Sergipe e entre a Serra da Capivara e a Serra das Confusões.
O sertão e a Caatinga estão muito bem retratados na arte brasileira. Na Literatura: Graciliano Ramos, Raquel de Queirós, José lIns do Rêgo, Guimarães Rosa, João Cabral de Melo Neto, Ariano Suassuna e Patativa do Assaré. No cinema, com os filmes "Deus e o Diabo na Terra do Sol", "Vidas Secas", "Baile Perfumado", "Abril Despedaçado", entre outros. Na música, há cantores como Luiz Gonzaga. Na literatura de cordel, há, também, inúmeras referências ao sertão como no Cordel do Fogo Encantado. Muito ricas, as manifestações culturais do sertanejo exprimem como o homem está envolvido com o ambiente em que vive. Infelizmente, essa, que é a parcela mais pobre do Brasil, também, é a mais vulnerável aos efeitos do aquecimento global por caus da seca e da desertificação.

Fonte: Biologia da Nova EJA - Seção "A riqueza do Brasil Central" Unidade "País tropical e bonito por natureza: os diferentes biomas". - p. 78 - Volume 2.

A linguagem, no trecho acima, está construída, em sua maior parte, de verbos no presente do indicativo, na terceira pessoa do singular e, em alguns casos, na terceira pessoa do plural, denotando grau de certeza por parte do enunciador, caracterizando a modalidade categórica. Esta apresentação, no presente do indicativo, expressa um grau de assertividade e certeza das informações sobre a Caatinga e os problemas ambientais em torno dela. O texto é dissertativo expositivo argumentativo, tipicamente vinculado aos contextos de desenvolvimento de uma informação. A defesa de que a Caatinga, por sua ampla riqueza na fauna e na flora, deve ser preservada, também, pode explicar o elevado número de verbos na modalidade categórica. $\mathrm{O}$ aspecto dissertativo é evidenciado em trechos nos quais os eventos são explicados ("O Rio São Francisco já formou uma imensa lagoa no interior do Brasil. A dinâmica da variação do seu curso, devido a alterações climáticas [...], criou barreiras geográficas que isolaram populações ...") e nos quais há emprego de verbos no pretérito perfeito como fundo para a argumentação dos eventos no presente do indicativo.

A maior parte dos períodos oracionais são construídos em um viés a mostrar dependência de uma cláusula ${ }^{7}$ em relação à outra, mas não são extensos. Há orações adjetivas como por exemplo: "Uma região com energia solar e que abriga um complexo hidrelétrico que fornece energia" $\left(6^{\circ}\right.$ parágrafo). Repare como estas orações, introduzidas pelo termo "que", estabelecem ideia de qualificação. Dão um caráter mais específico ao conteúdo explicado sobre o meio ambiente. $\mathrm{O}$ autor também optou por redigir períodos simples: "Aliás, o passado geológico da região é fasci-

7 O sinônimo de cláusula é oração. 
nante!" ( $5^{\circ}$ parágrafo). Isso imprime uma objetividade ao texto e pode facilitar o entendimento por parte do leitor. Para estabelecer coesão com o parágrafo anterior, o autor usou o elemento de coesão aliás, dando um caráter mais informal ao texto e enfatizando a importância da região descrita ao explicar a sua história.

O autor prossegue apresentando informações relevantes para a amplitude do conhecimento científico do aluno articulando Ciências da Natureza à Geografia e, no último parágrafo, à arte brasileira, ao mencionar as várias modalidades artísticas em que o sertão e a caatinga já foram retratados. Ao estabelecer esta interdisciplinaridade, o enunciador abre possibilidade ao aluno para perceber que os conteúdos podem ser trabalhados em várias disciplinas e, em cada uma delas, um aspecto será ressaltado e interligado a outros aspectos, respondendo a demandas postas em documentos curriculares para o ensino de ciências (PCNEM, 2002, p. 42).

Esse texto é um bom exemplo de preocupação do enunciador em representar o aluno como um ser capaz de apreender um conteúdo sobre uma vegetação, a Caatinga, que não existe no Rio de Janeiro, estado para o qual o livro da EJA é direcionado, e, mesmo assim, poder atuar para preservar os biomas brasileiros. Os aspectos sociais, históricos e políticos da região nordestina estão presentes no texto para favorecer a conscientização e o autor, ao usar um léxico apropriado para a ampliação do conhecimento, contribui para a participação social dos educandos levando-o a ser consciente do seu papel de atuação na sociedade do século XXI. Os aspectos gramaticais, como o uso dos verbos no presente, para denotar certeza, e os aspectos sintáticos, como os períodos oracionais curtos, com muitos pontos finais, podem contribuir para facilitar a compreensão e fazer o aluno da EJA perceber-se como um ser integrante da natureza e agente capaz de transformar o ambiente onde outras pessoas vivem.

A escolha por fazer referência a este tipo de bioma, para um público leitor do Estado do Rio de Janeiro, onde não há o tipo de vegetação estudado, cumpre a função de ampliar o âmbito de reflexão para além da paisagem imediatamente observável para os alunos. Ao mesmo tempo, pode trazer a alunos trabalhadores, que podem ter emigrado do Nordeste para o Sudeste do Brasil, e estarem estudando na EJA, um conhecimento científico sobre a sua região de origem.

Finalmente, a citação à literatura e ao cinema são aspectos interessantes. Evidenciam a preocupação do enunciador em trazer uma perspectiva interdisciplinar. Porém, não existem links ou qualquer direcionamento para facili- tar o acesso dos alunos a este conteúdo artístico e, assim, relacioná-lo ao sertão e à Caatinga.

\section{Conhecimento e necessidade que levam á tomada de decisão quanto ao meio ambiente}

\begin{abstract}
O controle biológico de pragas é um método usado como alternativa ao uso de pesticidas. A ideia é responder à invasão de uma praga com a introdução de inimigos naturais dela, como predadores ou parasitas específicos. Embora seja uma técnica recomendada para a agricultura orgânica, a introdução de espécies sempre gera riscos de desequilíbrios ecológicos e deve ser feita com cautela e sob a orientação de especialistas experientes.
\end{abstract}

Fonte: Biologia da Nova EJA - Seção "Saiba Mais"-p. 48-Volume 2

Vemos, no trecho destacado, sobre o método de controle biológico de pragas, que esta técnica, apesar de recomendada para a agricultura orgânica, "deve ser feita com cautela e sob a orientação de profissionais especializados", trecho no qual identificamos a modalidade deôntica, comprometimento com a obrigatoriedade/necessidade de ocorrência do evento enunciado. 0 texto introduz a noção de obrigação para a prática da agricultura orgânica e sugere fundamento para as tomadas de decisões apropriadas a partir do processo da informação oferecida. Não há, entretanto, a ampliação do conteúdo científico e um debate mais aprofundado em torno da questão. A informação é apresentada de forma normativa, autoritária e sem argumentos sobre o porquê da necessidade de cautela e de orientação de especialistas, a própria sessão já evidencia a apresentação de um conhecimento simplificado.

\section{Outro contexto associado à tomada de decisão que envolve saúde e meio ambiente}

A esquistossomose é uma doença causada por um agente infeccioso pertencente ao gênero Shistosoma. Este agente se abriga dentro de um molusco, o qual é um agente intermediário da transmissão da doença. A doença apresenta ciclos distintos. Em um primeiro ciclo da vida, com uma fase na água, o microorganismo está infectando o hospedeiro intermediário, o molusco aquático Biomphalaria.

Quando pessoas banham-se em águas com moluscos contaminados pelo Schistosoma, elas se contaminam, pois na água alguns plantelmintos conseguem penetrar na pele do humano. Assim, inicia-se outra fase, a 
fase terrestre da doença. A doença, raramente, mata pessoas, mas pode causar lesões na pele e, depois de muitos anos de infecção, chegar a danificar órgãos vitais e a retardar o desenvolvimento em crianças. Alguns dos sintomas mais comuns são inchaço, vermelhidão e coceiras na região onde houve a infecção. Em casos mais crônicos, pode haver inchaço da barriga das pessoas acometidas, motivo pelo qual essa doença também é conhecida como barriga d'água.

Podemos, portanto, dizer que existem dois hospedeiros para os parasitas da esquistossomose. Os hospedeiros intermediários, os moluscos, que abrigam os parasitas e os que transmitem para os hospedeiros finais, os humanos.

Fonte: Biologia da Nova EJA - Seção 2 "Sistema tegumentar" - Unidade "O corpo, a pele, os músculos e o esqueleto" - p. 15-Volume 1.

No trecho acima, percebe-se a preocupação do enunciador em informar o aluno de forma científica. As escolhas lexicais são apropriadas ao conteúdo do livro de Biologia. A linguagem utilizada é categórica, com a presença do verbo "ser", no presente do indicativo, como no período simples inicial "A esquistossomose é uma doença causada por um agente infeccioso pertencente ao gênero Schistosoma". Para estabelecer a coesão com o período anterior, o autor inicia o segundo período oracional com o pronome demonstrativo "este". Assim, localiza o leitor sobre a informação passada com o nome científico do agente infeccioso pertencente ao gênero Schistossoma.

A maior parte dos verbos (ser, apresentar, estar, banhar, contaminar, conseguir, iniciar, matar), neste excerto, estão expressos na modalidade categórica. Isso indica o grau de certeza científica, por parte do enunciador, em relação aos eventos científicos expressos e a atualidade do assunto.

Há a presença de três ocorrências da modalidade epistêmica ("pode causar", "pode haver" e "podemos dizer"), uma delas seguida do termo que contém ideia de oposição, "mas". Destacamos o período oracional por coordenação "A doença raramente mata pessoas, mas pode causar lesões na pele". Esse enunciado é expresso para informar ao aluno a baixa mortalidade por meio dessa doença. Porém, ao contrário do que se possa imaginar, por meio da ideia introduzida pelo termo de oposição "mas", o leitor deve se informar e, a partir do conhecimento científico, tomar a decisão de se cuidar, no caso de contrair a doença, para não ter sequelas como lesões na pele e, até, a danificação de órgãos vitais se a infecção persistir por muitos anos.

8 Um período oracional por coordenação é aquele em que as orações são independentes em termos de sentido.
O segundo parágrafo se inicia com um período onde há uma noção de temporalidade: "Quando pessoas banham-se em águas com moluscos contaminados pelo Schistosoma, elas se contaminam". A explicação para a contaminação está introduzida pelo termo explicativo "pois", no período "pois na água alguns platelmintos conseguem penetrar na pele do humano." Essa informação pretende conscientizar o leitor sobre a importância de não se banhar em qualquer água e tomar a decisão nesse sentido para preservar a sua saúde. Ainda neste parágrafo, a presença dos sintomas - inchaço, vermelhidão e coceiras na região onde houve a infecção - é uma forma de esclarecimento para ajudar o leitor a suspeitar da doença e tomar a decisão de procurar um médico.

O texto se encerra com uma informação científica importante em relação aos hospedeiros para os parasitas de esquistossomose: os intermediários são os moluscos, que abrigam os parasitas, e esses parasitas infectam os humanos que são os hospedeiros finais. Informação útil para a conscientização científica do estudante da EJA. Contribui para que o indivíduo desenvolva habilidades que 0 permitam utilizar os conhecimentos científicos para agir sobre a sua própria vida e tomar decisões responsáveis em seu cotidiano.

Nesta pesquisa, o estudo da modalidade se mostrou relevante para compreender como a linguagem do livro didático de Biologia e seu processo de construção quanto à forma das bases das certezas e da confiabilidade dos seus resultados são tratados nos livros didáticos de biologia para a EJA.

Analisamos, aliado aos aspectos conjunturais sobre formação deste aluno, como as escolhas sintáticas, lexicais, gramaticais e semânticas, que caracterizam as formulações presentes, nos livros didáticos de biologia, são apresentadas a fim de avaliar as relações entre os conteúdos de ciências e os contextos de participação social dos educandos. Vimos que a linguagem privilegia o uso de verbos expressando a modalidade epistêmica, forma mais aberta à aquisição do conhecimento para tomada de decisões, em detrimento da modalidade deôntica, forma mais normativa por meio da ideia de obrigatoriedade e categoricidade. Constatamos, também, por meio dessas formulações, se há ênfase no caráter crítico-emancipatório da educação em ciências, se o saber dos educandos é valorizado e/ou se existem formulações preconceituosas acerca de supostas deficiências científicas desses alunos jovens e adultos. Percebemos que a linguagem, destes livros, ao incentivar a tomada de decisão, motiva o aluno para ser crítico a partir dos conteúdos de biologia, mas ainda desconsidera o conhecimento trazido por este aluno para a escola. 
O conteúdo de biologia não reforça preconceitos sobre supostas deficiências, mas não aprofunda o tema ampliando as discussões, exigindo, assim, que o professor/mediador entre o autor e o aluno, em sala de aula, seja capaz de debater os assuntos não aprofundados como a questão da esquistossomose e do combate às pragas. Os conteúdos são trabalhados de forma reduzida, se comparado aos conteúdos de biologia para o ensino médio regular, conforme comenta Munakata (2012), em seus estudos sobre o livro didático.

Embora os conteúdos científicos estejam atendendo ao currículo mínimo, proposto pela SEEDUC, dentre os silenciamentos presentes, neste livro didático de biologia para a EJA, destacamos o fato de não serem problematizadas as questões sociais e nem tecnológicas associadas aos conteúdos científicos como propõe o documento curricular.

\section{Conclusões}

Neste estudo, analisamos os aspectos textuais envolvidos na apresentação de conhecimentos científicos, nos livros didáticos de biologia, para a EJA, e objetivamos perceber como esta materialidade se posiciona diante dos enunciados, como estes se organizam e como o discurso científico circula neste livro, muitas vezes, de forma normativa e autoritária, muitas vezes sem valorizar o suficiente o conhecimento potencial deste aluno. Essa concepção de mundo do enunciador, expressa no livro didático pelos verbos modais "dever" e "poder", principais verbos que caracterizam a modalidade, podem apontar para estereótipos acerca de supostas deficiências culturais. Os excertos analisados nos mostram que os autores e a parceria entre a SEEDUC e a Fundação CeCierj produzem um livro didático de biologia, onde o(s) autor(es) ainda se identificam como pessoas que possuem autoridade para abordar o assunto. A modalidade epistêmica, linguagem que mostra a preocupação do autor em trabalhar os conteúdos de forma mais suscetível ao conhecimento científico, assumindo a postura de quem detém um saber, mas sem considerar muito a experiência do aluno. Ou seja, há uma naturalização do social, conhecimento aparentemente não autoritário, mas que procura manter o status quo ao apresentar o conteúdo sem ampliá-lo o suficiente.

Fizemos um breve histórico da EJA, no início do trabalho, para mostrar as constantes propostas que levavam à exclusão, e a forma como o ensino de ciências, no livro de biologia, artefato cultural onde há a mediação das várias funções (referencial, instrumental, ideológica e documental), é trabalhado com um conteúdo muito diretivo. Os textos curtos, sem aprofundamento do assunto, com palavras e vocabulário científico sem complexidade, nos fazem concluir que o aluno da EJA representado, neste livro didático, é identificado como um sujeito que precisa de um conteúdo mais prático, sem ampliação dos saberes, e menos elaborado. Subentende-se, assim, que o saber mais elaborado é para os jovens que podem cursar o ensino médio regular e na faixa etária própria.

Considerando a importância do livro didático, conforme visto no início deste estudo, e o percurso histórico educacional dos alunos jovens e adultos, parcela mais desfavorecida, economicamente, percebe-se que, mesmo a linguagem do livro procurando encaminhar para um raciocínio que contribua para a tomada de decisão, a partir do conhecimento e certeza, conhecimento e assertividade, conhecimento e necessidade, em contextos de saúde e ambiente, nos quais os alunos necessitam ser autônomos, essa linguagem ainda está distanciada das Diretrizes Curriculares Nacionais que estabelecem as três funções da EJA: reparadora, qualificadora e equalizadora.

O livro didático de biologia, hoje, pode contribuir para este aluno da EJA, do Estado do Rio de Janeiro, se tornar emancipado, politicamente, incentivando a sua autonomia por meio de propostas de textos e exercícios, mais aprofundados na linguagem. Para isso, é necessária a inserção das questões envolvendo a Ciência, Tecnologia e Sociedade (CTS) aliadas aos conteúdos didáticos.

Na continuidade desta pesquisa, vamos ampliar a análise comparando o material, aqui estudado, aos fascículos da CEJA publicados pela SEEDUC em $2016^{9}$.

9 Rede CEJA (Centro de Educação de Jovens e Adultos) - www.cederj.edu.br Edição Revisada em 2016. sEeduc e Fundação CeCierj. Governador Luiz Fernando de Souza Pezão. 


\section{Referências}

Alvarenga, M. S (2010). Sentidos da cidadania: políticas de educação de jovens e adultos. Eduerj.

Amaral, W. R. (2000). Políticas de educação de jovens e adultos no Brasil: conceitos e contextos. Serviço Social em Revista Social, 3, 75-99.

Bakhtin, M. (1992). Marxismo e filosofia da linguagem: problemas fundamentais do método sociológico na Ciência da linguagem ( $9^{\mathrm{a}}$ ed.). Hucitec/Annablume.

Bittencourt, C. M. F. (2004). Autores e editores de compêndios e livros de leitura (1810-1910). Revista Educação e Pesquisa, III(30), 475-491.

BRASIL. PCN + Ensino Médio: orientações educacionais complementares aos Parâmetros Curriculares $\mathrm{Na}$ cionais. (2002) [PCN + Enseñanza Media: orientaciones educativas complementarias a los Parâmetros Curriculares Nacionales]. Volume Ciências da Natureza, Matemática e suas tecnologias. Brasília: MEC, SEF, pp.42-51.

Cachapuz, A. F. (1999). Epistemologia e ensino das ciências no pós-mudança conceptual: análise de um percurso de pesquisa. Atas do II ENPEC, Valinhos.

Carrano, P., Marinho, A. C., e Oliveira, V. N. M. (2015). Trajetórias truncadas: trabalho e estudo: jovens fora de série na escola pública de ensino médio. Revista Educação e Pesquisa, N. especial(4), 14391454, http://dx.doi.org./10.1590/51517970220150 8143413

Catelli, R. (2016). A EJA na Base Nacional Curricular Comum (BNCC). Revista Viver, Aprender. www. viveraprender.org.br/noticias/a-eja-na-base-nacional-curricular-comumbncc/

Chartier, R. (1997). Diálogos midiológicos 11. Da história da cultura impressa à história cultural do impresso. Revista Brasileira de Ciências da Comunicação, 28(1), 82-102.

Chopin, A. (2004). História dos livros e das edições didáticas sobre o estado da arte. Revista Educação e Pesquisa, III(30), 549-566.

Chouliaraki, L., e Fairclough, N. (1999). Discourse in late modernity. Edinburgh University Press.

Esteban, M. P. S. (2010). Pesquisa qualitativa em educação: fundamentos e tradições. AM GH Editora.
Fairclough, N. (2001). A análise crítica do discurso e a mercantilização do discurso público: as universidades. IEm C. Magalhães (Org.), Reflexões sobre a análise crítica do discurso (pp. 31-82).

Faculdade de Letras, UFMG.

Fairclough, N. (2003). Analysing discourse: textual analysis for social research. Routledge.

Ferraz, D., e Terrazzan, E. (2001). Uso espontâneo de analogias por professores de Biologia e o uso sistematizado de analogias: que relação? Ciência \& Educação, 9(2) 213-227.

Governo do Estado do Rio de Janeiro. (2018). Currículo Mínimo para a Educação de Jovens e Adultos. http://www.rj.gov.br/web/seeduc/exibeconteudo

Governo do Estado do Rio de Janeiro. (2013). Secretaria Estadual de Educação. Nova EJA-Educação para Jovens e Adultos - Ciências da Natureza e suas Tecnologias. [Nueva EJA-Educación para Jóvenes y Adultos-Ciencias de la Naturaleza y sus Tecnologías]. volumes 1 e 2 .

Hoffman, M. B., e Sheid, N. M. J. (2007). Analogias como ferramenta didática no ensino de biologia. Revista Ensaio, I(9), 21-37.

Krasilchik, M. (2000). Reformas e realidade: o caso do ensino de ciências. Perspectiva, I(14).

Lei de Diretrizes e Bases da Educação Nacional de 20 de dezembro de 1996. 9.394. http://www.planalto. gov.br/ccivil_03/LEIs/19394.html

Martins, I. (2008). Alfabetização científica: metáfora e perspectiva para o ensino de ciências. XI Encontro de Pesquisa em Ensino de Física. Curitiba. www. ciencia. Mao.up.br/dados/epef/_alfabetizacaocientificam.trabalho.pdf

Munakata, K. (2012). O livro didático: alguns temas de pesquisa. Revista Brasileira de História e Educação, III(12), 179-197.

Paiva, V. P. (1983). Educação popular e educação de adultos. Loyola.

Palmer. F. R. (1986). Mood and modality. Cambridge University Press.

Soares, M (2006). Letramento: um tema em três gêneros. Autêntica.

Parecer $n^{\circ} 11$, de 10 de maio de 2000. Diretrizes Curriculares Nacionais para a Educação de Jovens e Adultos, publicado no Diário Oficial da União de 9/6/2000, Seção 1e, p. 15. http://portal.mec.gov.br/ setec/arquivos/pdf1/proeja_parecer11_2000.pdf 